\title{
Job satisfaction and its relationship to Radiation Protection Knowledge, Attitude and Practice (RP- KAP) of Iranian radiation workers
}

\author{
S.S. Alavi ', S.T. Dabbagh ${ }^{2}$, M. Abbasi ${ }^{1}$ and R. Mehrdad ${ }^{7}$
}

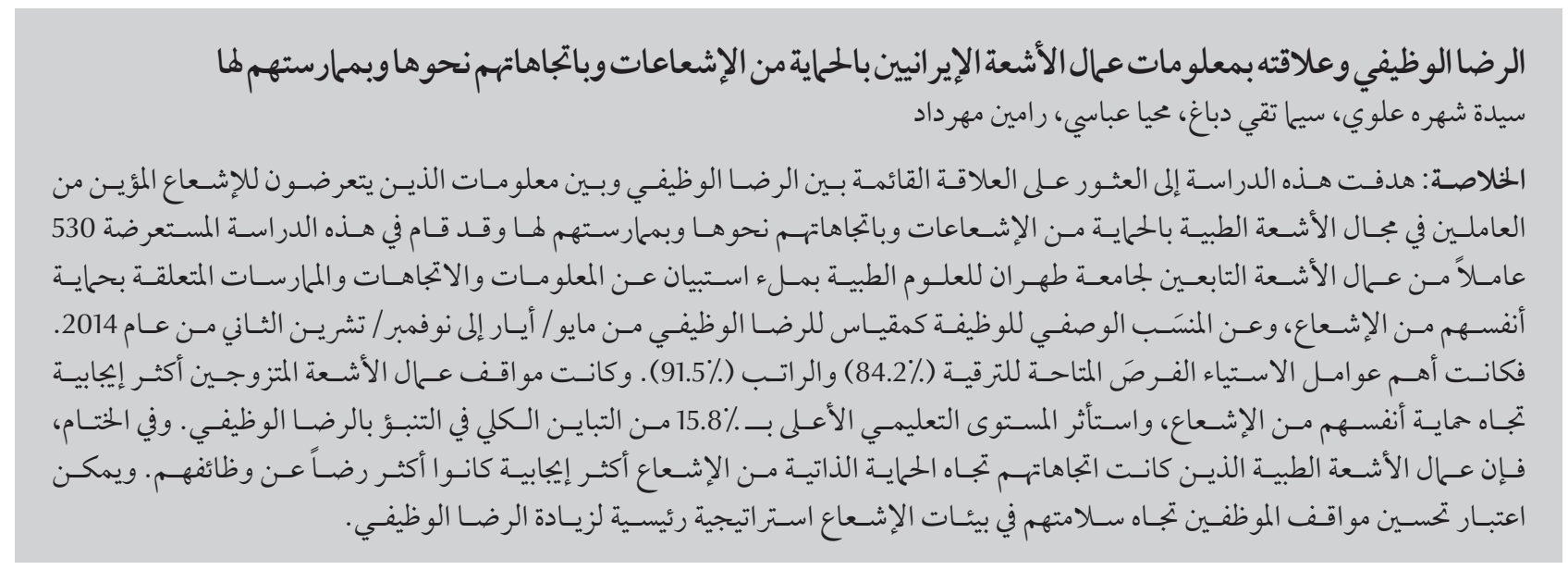

ABSTRACT This study aimed to find the association between job satisfaction and radiation protection knowledge, attitude and practice of medical radiation workers occupationally exposed to ionizing radiation. In this crosssectional study, 530 radiation workers affiliated to Tehran University of Medical Sciences completed a knowledge, attitude and practice questionnaire on protecting themselves against radiation and Job Descriptive Index as a job satisfaction measure during May to November 2014. Opportunities for promotion (84.2\%) and payment (91.5\%) were the most important factors for dissatisfaction. Radiation workers who were married, had more positive attitudes toward protecting themselves against radiation, and had higher level of education accounted for $15.8 \%$ of the total variance in predicting job satisfaction. In conclusion, medical radiation workers with a more positive attitude toward self-protection against radiation were more satisfied with their jobs. In radiation environments, improving staff attitudes toward their safety may be considered as a key strategy to increase job satisfaction.

Satisfaction au travail et lien avec les connaissances, attitudes et pratiques en matière de radioprotection des travailleurs iraniens exposés aux rayonnements

RÉSUMÉ La présente étude avait pour objectif de déterminer l'association entre la satisfaction au travail et les connaissances, attitudes et pratiques en matière de radioprotection des travailleurs exposés aux rayonnements médicaux ionisants dans le cadre de leur activité professionnelle. Au cours de cette étude transversale, 530 travailleurs exposés aux rayonnements rattachés à l'université de Sciences médicales de Téhéran ont rempli, entre mai et novembre 2014, un questionnaire portant sur les connaissances, attitudes et pratiques pour se protéger contre les rayonnements, ainsi que sur l'indice de satisfaction professionnelle Job Descriptive Index dans le but d'évaluer leur satisfaction au travail. Les possibilités de promotion (84,2 \%) et les salaires (91,5\%) étaient les facteurs les plus importants d'insatisfaction. Les travailleurs exposés aux rayonnements qui étaient mariés étaient davantage disposés à se protéger des rayonnements, et avaient un niveau d'éducation plus élevé représentant $15,8 \%$ de la variance totale relative à l'évaluation de la satisfaction au travail. En conclusion, les travailleurs exposés aux rayonnements médicaux ayant une attitude plus positive vis-à-vis du fait de se protéger étaient plus satisfaits de leur travail. Dans des environnements à rayonnement, améliorer la disposition du personnel à se protéger peut être considéré comme une stratégie clé pour augmenter la satisfaction au travail.

${ }^{\prime}$ Center for Research on Occupational Diseases, Tehran University of Medical Sciences, Tehran, Islamic Republic of Iran. ${ }^{2}$ Research Center for Science and Technology in Medicine, Tehran University of Medical Sciences, Tehran, Islamic Republic of Iran (Correspondence to: S.T. Dabbagh: alavi@tums.ac.ir).

Received: 06/08/15; accepted: 03/07/16 


\section{Introduction}

Working with radiation can be hazardous if protective and preventive measures are not observed and safety regulations are not taken into account (1). The International Commission on Radiological Protection (ICRP) as a primary body in protection against ionizing radiation classifies exposure in three categories: occupational exposure including dose limits for radiation workers, public exposure, and medical exposure. According to the ICRP, socioeconomic factors are important for limiting radiation exposure to as low as reasonably achievable (2). In addition, socioeconomic factors are essential features of job satisfaction. A complex interaction of several factors affects job satisfaction. Based on previous studies, the most common factors include the characteristics of the job, interaction with co-workers, immediate supervisor, job promotion and salary (3). It seems that manipulating these variables may increase or decrease the level of job satisfaction among employees. Job satisfaction can improve productivity and quality of life, reduce absenteeism, burnout and staff turnover, and improve quality of patient care as well as occupational safety (4).

Medical radiation workers are exposed to low-dose ionizing radiation through multiple sources and this situation compromises their health and safety (5). Radiation protection (RP) is one of the main factors that should be considered to protect employees' health and safety (6). A major part of health and safety protection at work is the core activities that employees need to carry out to maintain their own safety (7).

Previous research has indicated that job satisfaction is affected by improving skills and competencies of employees through participation in professional development and career advancement, and by safety at work (8). Only a few studies have addressed the relationship between job satisfaction and radiation workers' knowledge, attitude and practice (KAP) regarding protecting themselves against radiation in the Islamic Republic of Iran and worldwide. Therefore, the aim of the present study was to analyse whether RP-KAP of Iranian medical radiation workers can predict their level of job satisfaction.

\section{Methods}

\section{Study population and data collection}

This cross-sectional survey was conducted in Tehran University of Medical Sciences (TUMS), Islamic Republic of Iran from May to November 2014. All radiation workers in all 16 governmental referral hospitals affiliated to TUMS, comprising physicians, nurses and technologists, were asked to complete a comprehensive questionnaire anonymously. We used the census sampling method and one of the researchers distributed the questionnaires by hand at the workplaces of the participants. Participants completed the questionnaires within a maximum of 12 minutes. In total, 530 of 720 questionnaires were returned, representing a response rate of $73.6 \%$.

Participants gave written informed consent after receiving information about the aims and protocol of the survey and they were assured regarding the confidentiality of their data. Participation in this study was voluntary and the participants could stop the data collection process at any time. The Medical Ethics Committee of TUMS approved the research.

\section{Measures}

The research instrument was a self-administered questionnaire that included 3 sections. The first section was general characteristics of the participants: sex, age, educational level, marital status, years of experience working with radiation, field of study at the university including radiology or other fields in medical education, and participation in in-service training programmes over the past year. The second section was a modified version of the Job Descriptive Index (JDI) as a cognitive job satisfaction measure, which was first developed by Smith et al. (9). The JDI included 5 subscales: the nature of the work itself (10 questions); attitudes towards supervisors (8 questions); relations with co-workers (10 questions); opportunities for promotion (5 questions); and payment (6 questions). All 39 questions of the JDI were measured using 5-point Likert scales from least (score 1) to highest (score 5) occupational satisfaction. The score of each subscale and total job satisfaction for each participant were calculated by the following equations (9):

\section{Score of each subscale $=$}

Sum of scores of all items in each subscale Total number of items in each subscale

\section{Score of total job satisfaction $=$}

Sum of scores of all subscale

Total number of items in each subscale

Construct validity and reliability of the Iranian version of the JDI questionnaire (Cronbach's $\alpha=0.94$ ) was already approved (10).

The third section was a 32 -item questionnaire consisting of 13 questions to evaluate RP knowledge, 13 questions about attitude and 6 questions related to practice, developed based on the most common experiences and issues that researchers encountered, as well as approved protocols and radiation safety guidelines. To evaluate content validity of the questionnaire, the content validity ratio (CVR) and content validity index (CVI) were used. Ten experts with different educational backgrounds (including educational planning, epidemiology, radiology and occupational health) assessed the questionnaire content in terms of asking the right questions and avoiding ambiguity. The CVR of the questionnaire constructs was $0.61-0.76$ and CVI structure was 
$0.77-0.93$. To measure the face validity of the questionnaire, 30 radiation workers and the 10 previously mentioned experts rated each question in terms of clarity, understandability and length of each question. Face validity was ensured by the revision of 7 items. To determine the reliability of the questionnaire, Cronbach's $\alpha$ was calculated (0.92). To determine participants' level of KAP, a numerical value was assigned to each correct answer: knowledge (1.54), attitude (1.54) and practice (3.33). The minimum and maximum scores were 0 and 20 for each set of RP-KAP questions. In this way, a score could be calculated for each participant in relation to the highest possible score.

\section{Data analysis}

All data was analysed using SPSS version 21. We used descriptive statistics to describe our populations' general characteristics. We compared quantitative variables between two groups using the Mann-Whitney U test. We set total job satisfaction as a dependent variable in a multiple linear logistic model to find predictors of higher job satisfaction scores only for the significant factors in univariate analysis. Total job satisfaction was categorized into 2 levels: low satisfaction (scores 1-3) and high satisfaction (scores 3.1-5).

\section{Results}

Five hundred and thirty radiation workers participated in this study. There were 341 women $(64.3 \%)$ and 189 men (35.7\%), with a mean age (SD) of 33.7 (15.7) years. Three hundred and forty-seven (65.5\%) participants were married and 183 (34.5\%) were unmarried. Three hundred and twentythree $(61 \%)$ had a degree in radiology and 207 (39\%) were other medical specialists who worked professionally with radiation. Level of education was: bachelor's degree (70.6\%), lower than bachelor's degree (18.7\%) and higher degree (10.7\%). The participants had a mean (SD) 9.2 (7.5) years experience with radiation, and 335 (63.2\%) had undertaken in-service training and 195 (36.8\%) had not.

Analysis of responses to each subscale of the JDI questionnaire indicated the levels of job satisfaction. A score of 1-3 represented low satisfaction and a score of 3.1-5 high satisfaction. A high percentage of participants, regardless of profession, felt unsatisfied with the nature of their work (50.6\%), their supervisors (41.5\%), interaction with their colleagues $(33.6 \%)$, opportunities for promotion ( $84.2 \%)$, and payment (91.5\%). More than half of respondents (53.5\%) perceived job dissatisfaction.

General characteristics were not associated with participants' satisfaction with opportunities for promotion and interaction with their colleagues (Table 1). Radiation workers with a degree in radiology were less satisfied with their supervisors and nature of their work and more satisfied with their payment. In addition, there was no relationship between job training and subscales of job satisfaction, except attitudes towards supervisors $(P=0.04)$.

Radiation workers who had more years of experience with radiation were significantly satisfied with their coworkers $(r=0.14, P=0.002)$, however, they were less satisfied with opportunities for promotion $(r=0.1, P=0.03)$ (Table 2).

The relationship between self-rated RP-KAP and job satisfaction showed that a more positive attitude toward selfprotection was associated with higher total job satisfaction $(P<0.001)$ and with all its subscales, including nature of the work $(P<0.001)$, interaction with colleagues $(P=0.006)$, attitudes towards supervisors $(P=0.009)$, opportunities for promotion $(P=0.017)$ and payment $(P<0.001)$ (Table 3$)$.

Additional linear logistic regression was conducted to assess the ability of significantly correlated factors such as marital status, in-service training, field of study, levels of education, years of work experience with radiation, as well as RP-KAP to predict job satisfaction (Table 4). Significant predictors including positive attitude toward self-protection against radiation, higher levels of education and being married. The $R^{2}$ of the linear regression model was 0.158 $(F=12.5, P<0.001)$. Field of study $(P=0.013)$, in-service training during last year $(P=0.1)$ and years of experience with radiation $(P=0.7)$ were not associated with job satisfaction.

\section{Discussion}

The major focus of this study was an analysis of the link between radiation workers' job satisfaction and their RP-KAP about protecting themselves against radiation in governmental referral hospitals affiliated to TUMS. More than half of all radiation workers felt total dissatisfaction. Consistent with our study, Magnavita et al. (11) declared that only $49 \%$ of diagnostic radiologists were satisfied with their jobs. Another study among oncology staff in radiation oncology departments in New Zealand found a high level of job satisfaction (3.75 mean score out of 5) (12).A2013 study of Japanese radiologists reported that $67.8 \%$ respondents were very or somewhat satisfied with their current job (13). Job satisfaction is a subjective and attitudinal issue that is influenced by individuals' wants, desires and many cultural and socioeconomic factors, so it varies from person to person. Furthermore, measuring job satisfaction can be challenging and there is no general agreement on the best and standard method of measurement.

Among the 5 subscales of the JDI questionnaire, the highest level of dissatisfaction was observed for payment and promotion. Other dissatisfiers, in order, were the nature of the work, supervisors and co-workers. Previous research about the most common dissatisfiers 


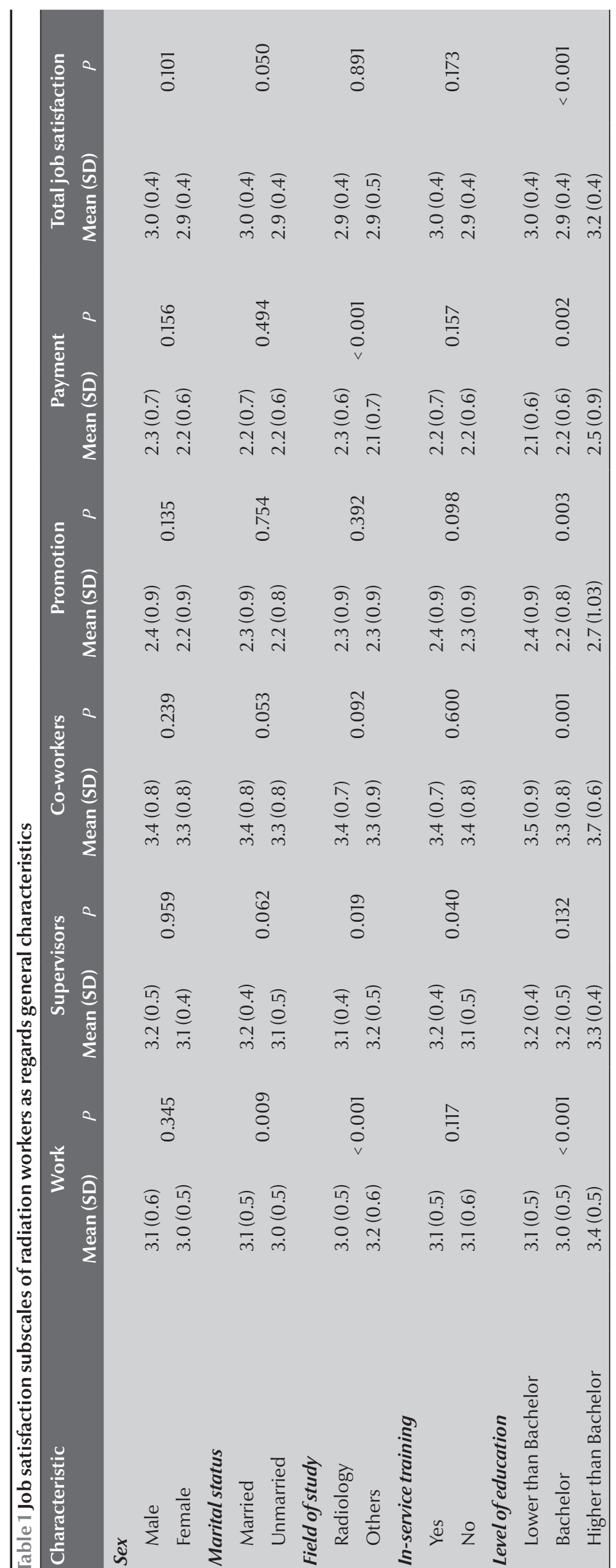

support our findings (13). Our participants were more satisfied with interaction with their co-workers than the other subscales. In line with the present survey, another study showed that one of the most common sources of professional satisfaction was the appreciation shown by radiologists' supervisors and colleagues (14). In the study of Graham et al. (15), one of the most important sources of job satisfaction was "being perceived to perform the duties properly by co-workers". Another study of job satisfaction level among 8 healthcare profession groups indicated that radiation workers were more satisfied in terms of supervision, co-workers, and the nature of the work (16). That study found significant differences in terms of satisfaction related to promotion, supervision, co-workers and the nature of the work, but not in terms of payment. Our findings suggested that administrators could affect satisfaction by defining a reward system and ways to pay fair salaries, as well as facilitating job promotion for eligible radiation workers. Employers often have limited financial capacity to increase salaries and their budget may not meet the satisfaction of all employees. However, promotions are not necessarily limited to pay increases and can be awarded based on employees' interests and values. Examples of promotion include offices with more advanced facilities and space; acknowledgement and positive feedback to perform a worthy activity; respect; highly valuing the position occupied by employees and increasing authority over co-workers. Workers' expectation of job promotion has an important role in the effectiveness of promotion and increasing occupational satisfaction. In addition, promotion may mitigate the impact of dissatisfaction caused by low payments resulting from the limited financial capacity of employers. In the present study, participants were more satisfied with their co-workers, supervisors and the nature of their work. It seems that these factors are harder to manipulate and require a large investment of time and money.

Although most respondents were dissatisfied in terms of payment, participants with a degree in radiology were more satisfied. In contrast, despite the high satisfaction in terms of the nature of the work and supervisors among all participants, respondents with a degree in radiology reported less satisfaction. 


\begin{tabular}{|c|c|c|c|c|c|c|c|c|c|c|c|c|}
\hline \multirow[t]{2}{*}{ Characteristic } & \multicolumn{2}{|c|}{ Work } & \multicolumn{2}{|c|}{ Supervisors } & \multicolumn{2}{|c|}{ Co-workers } & \multicolumn{2}{|c|}{ Promotion } & \multicolumn{2}{|c|}{ Payment } & \multicolumn{2}{|c|}{$\begin{array}{c}\text { Total job } \\
\text { satisfaction }\end{array}$} \\
\hline & $r$ & $P$ & $r$ & $\boldsymbol{P}$ & $r$ & $\boldsymbol{P}$ & $r$ & $\boldsymbol{P}$ & $r$ & $\boldsymbol{P}$ & $r$ & $P$ \\
\hline Age (years) & 0.02 & 0.7 & 0.05 & 0.2 & 0.09 & 0.06 & -0.01 & 0.8 & 0.005 & 0.9 & 0.06 & 0.2 \\
\hline Experiences with radiation (years) & 0.02 & 0.6 & 0.08 & 0.07 & 0.14 & 0.002 & -0.10 & 0.03 & 0.04 & 0.3 & 0.07 & 0.1 \\
\hline
\end{tabular}

A possible explanation is that graduates in radiology are interested in their jobs and low payments are tolerable. However, they may have more information about their workplace hazards, especially the potential risk of radiation exposure, and it seems they are more concerned regarding the nature of their job. Moreover, they expect supervisors to try their best to mange workplace hazards where appropriate, control the quality of equipment, and take responsibility for occupational health and safety. Therefore, dissatisfaction with work conditions and supervisors may be more likely.

Neither total job satisfaction nor its subscales were related to sex, which was similar to previous studies $(3,17)$. In addition, in-service training was not linked to total job satisfaction, which was also consistent with previous research (18). However, a previous study reported that in-service training and rewarding employees' performance and competence with promotion led to greater job satisfaction (19). The lack of association between in-service training and total job satisfaction has several possible explanations. First, healthcare workers in the hospitals in our study were traditionally encouraged to participate in in-service training, which was neither perceived necessary by them nor planned based on their educational needs. Second, training programmes that were not related to employees' main tasks might have underestimated the worth of the most important performance criteria, and consequently, dissatisfaction might have increased. Third, most of the training programmes used ineffective methods that were not in accordance with employees' learning style. Therefore, in-service training did not attract participants.

According to the regression analysis, job satisfaction and radiation workers' attitude toward self-protection were associated. From practical and research perspectives, employees' attitudes, opinions and concepts regarding various aspects of their job and work environment influence their job satisfaction (20).

\begin{tabular}{|c|c|c|c|c|c|c|}
\hline \multirow{2}{*}{ Job satisfaction } & \multicolumn{2}{|c|}{ Knowledge } & \multicolumn{2}{|c|}{ Attitude } & \multicolumn{2}{|c|}{ Practice } \\
\hline & Mean (SD) & $P$ & Mean (SD) & $P$ & Mean (SD) & $P$ \\
\hline \multicolumn{7}{|l|}{ Work } \\
\hline Low & $6.8(3.3)$ & \multirow{2}{*}{0.109} & $8.0(2.4)$ & \multirow{2}{*}{$<0.001$} & $11.9(4.2)$ & \multirow{2}{*}{0.003} \\
\hline High & $7.4(3.5)$ & & $9.4(2.7)$ & & $13.0(3.5)$ & \\
\hline \multicolumn{7}{|l|}{ Supervisors } \\
\hline Low & $7.1(3.5)$ & \multirow{2}{*}{0.957} & $8.3(2.7)$ & \multirow{2}{*}{0.009} & $12.2(4.4)$ & \multirow{2}{*}{0.737} \\
\hline High & $7.1(3.4)$ & & $8.9(2.6)$ & & $12.5(3.6)$ & \\
\hline \multicolumn{7}{|l|}{ Co-workers } \\
\hline Low & $6.8(3.4)$ & \multirow{2}{*}{0.333} & $8.2(2.6)$ & \multirow{2}{*}{0.006} & $11.6(4.4)$ & \multirow{2}{*}{0.004} \\
\hline High & $7.2(3.5)$ & & $8.9(2.6)$ & & $12.8(3.6)$ & \\
\hline \multicolumn{7}{|l|}{ Promotion } \\
\hline Low & $7.1(3.4)$ & \multirow{2}{*}{0.778} & $8.5(2.6)$ & \multirow{2}{*}{0.017} & $12.4(4.0)$ & \multirow{2}{*}{0.815} \\
\hline High & $7.2(3.5)$ & & $9.3(2.8)$ & & $12.3(3.7)$ & \\
\hline \multicolumn{7}{|l|}{ Payment } \\
\hline Low & $7.0(3.4)$ & \multirow{2}{*}{0.002} & $8.5(2.6)$ & \multirow{2}{*}{$<0.001$} & $12.4(4.0)$ & \multirow{2}{*}{0.547} \\
\hline High & $8.6(3.4)$ & & $10.1(2.8)$ & & $13.0(3.5)$ & \\
\hline \multicolumn{7}{|c|}{ Total job satisfaction } \\
\hline Low & $7.0(3.5)$ & \multirow{2}{*}{0.585} & $8.0(2.5)$ & \multirow{2}{*}{$<0.001$} & $12.1(4.2)$ & \multirow{2}{*}{0.140} \\
\hline High & $7.2(3.4)$ & & $9.3(2.7)$ & & $12.7(3.6)$ & \\
\hline
\end{tabular}

Low satisfaction $=$ scores $1-3$, high satisfaction $=$ scores 3.1-5. 


\begin{tabular}{|c|c|c|c|c|c|c|}
\hline \multirow[t]{2}{*}{ Variable } & \multirow[t]{2}{*}{ B } & \multirow[t]{2}{*}{ SE } & \multirow[t]{2}{*}{$P$} & \multirow[t]{2}{*}{ OR } & \multicolumn{2}{|c|}{$95 \% \mathrm{Cl}$ for $\mathrm{OR}$} \\
\hline & & & & & Lower & Upper \\
\hline RP Attitude & 0.19 & 0.04 & $<0.001$ & 1.2 & 1.1 & 1.3 \\
\hline Marital status (married) & -0.44 & 0.20 & $<0.001$ & 0.64 & 0.38 & 0.98 \\
\hline Level of education (higher than Bachelor's) & 0.39 & 0.10 & $<0.001$ & 1.48 & 1.18 & 1.85 \\
\hline Constant & -3.3 & 0.9 & $<0.001$ & - & - & - \\
\hline Total $R^{2}$ & \multicolumn{6}{|c|}{0.158} \\
\hline $\mathrm{F}(P)$ & \multicolumn{6}{|c|}{$12.5(<0.001)$} \\
\hline
\end{tabular}

This is in line with previous research, which revealed that workers with higher safety perception expressed more job satisfaction compared to others (21). Radiation is considered to be an external factor that contributes to difficult working conditions. Workers with difficult working conditions have lower job satisfaction compared to those with normal working conditions (22). Improvement of safety at work, providing protective equipment and information, and urging employees to follow safety rules and procedures ensure a safe working environment, and reduce negative attitudes toward safety and unnecessary fear and anxiety over radiation exposure. In this regard, workers who perceive their workplace as safe experience lower levels of occupational anxiety and face fewer hazards (23). Further research has revealed that job-related anxiety and negative attitudes in the workplace are among the variables that adversely correlate with the level of job satisfaction (24). Therefore, improving attitudes of radiation workers toward their safety may be one of the effective strategies to increase job satisfaction.

Our findings showed that RP-KAP did not predict job satisfaction. Previous studies have found that constant professional development and improving staff capabilities in the workplace are principal sources of job satisfaction $(25,26)$. In addition, Abushaikha and SacaHazboun have revealed that providing opportunities for professional development increases job satisfaction (27). Kaila has found that behaviour-based safety leads to higher job satisfaction (28). On the contrary, Hayes et al. have reported that management safety practices and supervisor safety subscales are good predictors of job satisfaction but workers' safety is not (23). Another study investigating the link between job satisfaction and workers' safety performance has shown that workers with greater job satisfaction are often safer workers. Conversely, safe workers are not necessarily satisfied (29).

We found that higher level of education was among 3 factors that predicted job satisfaction. This result was expected because attaining a higher university degree compared to lower degrees contributes to a feeling of coherence, success at work, personal growth and self-respect, self-realization and intrinsic motivation. The combination of all these factors contributes to generating a sense of job satisfaction.

We found that marital status was a predictor contributing to job satisfaction. The relationship between these 2 variables has been extensively investigated. However, there is controversy about their relationship. In some investigations, married employees experienced a higher level of job satisfaction than their unmarried co-workers (30), while in others, marital status did not predict job satisfaction (31). The positive relationship between the 2 variables in the present study may have several explanations. First, marriage imposes certain responsibilities and makes a permanent job offer a top priority. Therefore, employees, in many cases, try to cope with their job conflicts, adjust them, or resolve any workplace problems. As a result, job satisfaction increases. Second, married employees have opportunities to receive support or advice from their family to mediate job conflicts. The result can be increased job satisfaction.

This study had some limitations. Job satisfaction has a subjective nature and depends on employees' wants, desires and opinions. Therefore, it varies from person to person and its predictors in each society and organization are difficult to predict. Surveys such as ours assess a small set of potentially related variables and can only provide managers with specific information related to their own working environment. Therefore, there is no one-size-fits-all plan to improve occupational satisfaction. In this regard, it is noteworthy that, the low level of total $R^{2}$ of the regression model assessing predictors of job satisfaction did not neutralize other significant predictors. This means there are more factors affecting job satisfaction and further research is needed to identify them. In addition, job satisfaction is a state of mind, so it is not a constant feeling. Assessment of its influencing factors and the magnitude of each one over time can provide organizations with clues to plan programmes in order to increase employees' satisfaction. Therefore, measuring job satisfaction using longitudinal methods is more useful and recommended. Furthermore, it was not possible to evaluate content, structure and effectiveness of previous RP 
training programmes. Interventional studies to assess the effectiveness of RP training programmes and their relationship with job satisfaction are recommended.

In conclusion, job dissatisfaction among medical radiation workers was high. Job satisfaction is multifaceted and is influenced by more than just a single element. RP attitude, marital status and level of education were found to influence job satisfaction. Future studies can help to find other factors that influence job satisfaction and improve employees' feelings regarding their work environment. It is hoped that this study will serve as an important platform for future detailed surveys and the findings will encourage radiology managers and administrators to find useful means to improve radiation workers' safety and job satisfaction in working lives.

Funding: This research was financially supported by the Vice-Chancellor for Research of TUMS through contract no. 93-02-109-25389.

Competing interests: None declared.

\section{References}

1. ALMasri HY. Kakinohana Y, Yogi T. Occupational radiation monitoring at a large medical center in Japan. Radiol Phys Technol. 2014 Jul;7(2):271-6. PMID:24570292

2. International Commission on Radiological Protection. Recommendations of the International Commission on Radiological Protection. ICRP publication 103. Elsevier; 2007.

3. Parvin MM, Kabir MMN. Factors affecting employee job satisfaction of pharmaceutical sector. Aust J Bus Manag Res. 2011 Dec;1(9):113-23.

4. Knight A. Nuclear medicine technologist job satisfaction. J Nucl Med Technol. 2004 Dec;32(4):220-8. PMID:15576345

5. Vendramin A, Bilban M. Occupational exposure to ionizing radiation for medical workers. Slovenian J Public Health. 2012 Jan;51(3):182-9.

6. Occupational radiation protection: protecting workers against exposure to ionizing radiation. Proceedings of an international conference held in Geneva, Switzerland, 26-30 August 2002. Vienna: International Atomic Energy Agency; 2003 (http:// www-pub.iaea.org/MTCD/Publications/PDF/Pub1145_web. pdf, accessed 30 August 2016).

7. Oostakhan M, Mofidi A, Davudian Talab A. Behavior-based safety approach at a large construction site in Iran. Iran Rehabil J. 2012 Feb;10:21-5.

8. Dieleman M, Harnmeijer J. Improving health worker performance: In search of promising practices, evidence and information for policy. Geneva: Department of Human Resources for Health, World Health Organization; 2006 (http://www. who.int/hrh/resources/improving_hw_performance.pdf, accessed 30 August 2016).

9. Smith PC, Kendal LM, Hulin CL. The measurement of satisfaction in work and retirement: a strategy for the study of attitudes. Chicago: Rand McNally; 1969.

10. Naghibzadeh SB, Amiri H. Comparing job satisfaction, depression and anxiety among ordinary and extraordinary primary schools' teachers. Epistemologia. 2014;11(2):173-82.

11. Magnavita N, Fileni A, Bergamaschi A. Satisfaction at work among radiologists. Radiol Med. 2009 Dec;114(8):1330-44. PMID:19789957

12. Jasperse M, Herst P, Dungey G. Evaluating stress, burnout and job satisfaction in New Zealand radiation oncology departments. Eur J Cancer Care (Engl). 2014 Jan;23(1):82-8. PMID:23844995

13. Sone M, Mizunuma K, Nakajima Y, Yasunaga H, Ohtomo K. Job satisfaction, income, workload, workplace, and demographics of Japanese radiologists in the 2008 survey. Jpn J Radiol. 2013 May;31(5):364-70. PMID:23430397

14. Czekajska-Chehab E, Drop A, Okła W. Satisfaction and stress factors in the radiologist's profession. Ann Univ Mariae Curie Sklodowska Med. 2003;58(1):261-7. PMID:15314996
15. Graham J, Ramirez AJ, Field S, Richards MA. Job stress and satisfaction among clinical radiologists. Clin Radiol. 2000 Mar;55(3):182-6. PMID:10708609

16. Chen $\mathrm{AH}$, Jaafar $\mathrm{SN}$, Noor AR. Comparison of job satisfaction among eight health care professions in private (nongovernment) settings. Malays J Med Sci. 2012 Apr;19(2):19-26. PMID:22973134

17. Beitzel KI, Ertl L, Grosse C, Reiser M, Ertl-Wagner B. Berufszufriedenheit von radiologen in Deutschland - aktueller stand [Job satisfaction of radiologists in Germany - status quo]. Rofo. 2011 Aug;183(8):749-57 (in German). PMID:21506073

18. Jin $M H$, Lee MY. The effects of autonomy, experience, and person-organization fit on job satisfaction: the case of public sector. Int J Soc Sci. 2012 Dec;6(1):18-44 (http://www.tijoss. com/6thVolume/Myung.pdf, accessed 30 August 2016).

19. Lee $\mathrm{CH}$, Bruvold NT. Creating value for employees: investment in employee development. Int J Hum Resour Manag. 2003;14(6):981-1000 (http://www.mobilityagenda.org/value.pdf, accessed 30 August 2016).

20. Ayeni CO, Phopoola SO. Work motivation, job satisfaction and organizational commitment of Library Personnel in Academic and Research Libraries in Oyo State. Nigeria: Library Philosophy and Practice; 2007.

21. Gyekye SA, Salminen S. Workplace safety perceptions and perceived organizational support: do supportive perceptions influence safety perceptions? Int J Occup Saf Ergon. 2007;13(2):189-200. PMID:17599793

22. Bakotić D, Babić T. Relationship between working conditions and job satisfaction: the case of Croatian Shipbuilding Company. Int J Bus Soc Sci. 2013 Feb;4(2):206-13 (http://ijbssnet. com/journals/Vol_4_No_2_February_2013/22.pdf, accessed 30 August 2016).

23. Hayes BE, Perander J, Smecko T, Trask J. Measuring perceptions of workplace safety: development and validation of the work safety scale. J Safety Res. 1998 Autumn;29(3):145-61.

24. Zalewska AM. Relationships between anxiety and job satisfaction- Three approaches: 'Bottom-up', 'top-down' and 'transactional'. Pers Individ Dif. 2011 May;50(7):977-86.

25. Chen TY, Chang PL, Yeh CW. An investigation of career development programs, job satisfaction, professional development and productivity: the case of Taiwan. Hum Resour Dev Int. 2004;7(4):441-63.

26. Lu H, While AE, Barriball KL. Job satisfaction among nurses: a literature review. Int J Nurs Stud. 2005 Feb;42(2):211-27. PMID:15680619

27. Abushaikha L, Saca-Hazboun H. Job satisfaction and burnout among Palestinian nurses. East Mediterr Health J. 2009 JanFeb;15(1):190-7. PMID:19469443 
28. Kaila H. Behavior based safety in organizations. Indian J Occup Environ Med. 2006;10(3):102-6 (http://www.ijoem.com/ article.asp?issn=0019-5278; year=2006; volume=10;issue=3;sp age=102; epage=106; aulast=Kaila, accessed 30 August 2016).

29. Blair E. Behavior-based safety: myths, magic reality. Prof Saf 1999 Aug;44(8):25-9.
30. Clark AE. Job satisfaction in Britain. Br J Ind Relat. 1996 Jun;34(2):189-217.

31. Saner T, Eyüpoğlu ŞZ. The gender-marital status job satisfaction relationship of academics. Procedia Soc Behav Sci. 2013 Dec;106:2817-21. 